\title{
Adaptation aux cellules rénales de lapin de virus associés à la dermatose nodulaire bovine
}

\author{
par J. RAMISSE, H. SERRES, E. RAKOTONDRAMARY
}

\begin{abstract}
RÉSUMÉ
Nous avons adapté les souches locales et NEETHLING, agents de la dermatose nodulaire aux cellules rénales de lapin. Elles provoquent la destruction des cellules et la formation d'inclusions cytoplasmıques. Après un certain nombre de passages les souches virales sont encore pathogènes pour le veau. La séroneutralisation montre l'identité entre les souches locales et NEETHLING. Elles ne sont pas hémagglutinantes. Leur acide nucléique est de l'ADN.
\end{abstract}

Les virus isolés au cours de la dermatose nodulaire onł pu être cultivés solt sur embryons de poulet, soit sur cellules en culture. Sur embryons de poulet, VAN DEN ENDE et Coll. (1948) ont Isolé un virus «orphelin», et HAIG (1949), un virus pathogène. En 1959, VAN ROOYEN ef Coll. ont passé sur embryon un virus type NEETHLING adapté aux cultures cellulaires. Ce virus n'étalt pas létal pour l'embryon, mais il provoquait la formation de pustules. Sur cultures de cellules rénales de veau, ALEXANDER et Coll. $(1956,1957)$ ont isolé et caractérisé différentes souches virales qui ont été réparties en 3 groupes : groupe I (type BZD), groupe II (type ALLERTON), groupe III (type NEETHLING). M. de LANGE (1959) a bien mis en évidence les différences entre les effets cytopathogènes propres à chaque groupe. PRYDIE et Coll. (1959) ont cultivé leurs souches sur cellules rénales de veau, d'agneau, et de fotus ovin, sur cellules testicularres de veau et d'agneau, ainsi que sur une lignée de cellules rénales d'agneau. Ils n'ont pas réussi à les cultiver sur HELA. Selon WEISS (1964), les cellules rénales d'agneau et de veau, et les cellules testiculaires d'agneau sont les systèmes les plus sensibles.

Ayant isolé sur cellules rénales de veau (lignée cellulaire), quelques souches locales de virus associés à la dermatose, et ne disposant pas de cellules rénales primaires de veau ou d'agneau, nous avons essayé d'adapter aux cellules rénales primaires de lapin, les souches virales locales, aınsı que des souches reçues d'Afrique du Sud.

\section{TECHNIQUES D'ÉTUDE}

\section{Origine des souches.}

Nous avons étudié comparativement les 4 souches locales, et les souches Sud-Africannes (NEETHLING, ALLERTON, BZD). Les souches locales étaient entretenues sur cellules rénales de veau (lignée cellulaire). Nous les avons passées sur cellules rénales de lapın lorsque l'effet cytopathogène sur cellules rénales de veau a été net et constant. Les souches Sud-Africaines étaient également passées sur cellules rénales de veau, ou conservées lyophilısées au congélateur. 
$2^{\circ}$ Système cellulaire utilisé eł mode de passage.

Nous avons mis en culture, selon la méthode classique par trypsination, des cellules rénales de lapereau de mons de 15 jours. Le milieu de croissance contenait de l'hydrolysat de lactalbumine en solution de EARLE, 10 p. 100 de sérum de veau local, et la concentration habituelle d'antibiotiques. Le $\mathrm{pH}$ du milieu était ajusté à 6,8-6,9. Pour l'entretien nous utilisions le milieu de EAGLE (Basal Eagle Medium) reconstitué à partir de la présentation desséchée, et additionné de 5 p. 100 de sérum de veau importé, de bicarbonate $(\mathrm{pH}: 7,5-7,6)$, et d'antibiotiques. Durant l'incubation ( $5-6$ jours à $37{ }^{\circ} \mathrm{C}$ ) des cellules inoculées, le milieu était renouvelé une fols, si nécessaire, avant la lyse avancée des cellules. Pour le transfert des souches virales, nous inoculions la suspension de cellules infectées du passage précédent $(0,5 \mathrm{ml}$ par tube). Les cellules infectées étaient détachées du verre par grattage lorsque la lyse était incomplète. Le passage des cellules rénales de veau aux cellules rénales de lapin s'est fait de la même façon. L'examen quotidien des tubes inoculés nous permettait de noter l'apparition de l'effet cytopathogène. Les cultures sur lamelles ont été colorées à l'hématéine-éosine pour mettre en évidence les inclusions. A plusieurs reprises nous avons essayé de titrer les souches qui se développaient sur cellules rénales de lapin.

30 Influence de la température d'incubation, de la concentration en sérum, et de la composition du milieu.

Certains auteurs (VAN ROOYEN et Coll., 1959 - WEISS et Coll., 1959) ont observé que la température optimale d'incubation étalt de $33,5^{\circ} \mathrm{C}$ à $35^{\circ} \mathrm{C}$ pour les embryons inoculés, et de $36^{\circ} \mathrm{C}$ pour les cellules infectées avec les virus de la dermatose nodulaire. Nous avons voulu nous rendre compte si, en variant entre $35^{\circ} \mathrm{C}$ et $38^{\circ} \mathrm{C}$ la température d'incubation des cellules rénales de lapin inoculées, nous obtenions une amélioration dans la production du virus. De même en essayant plusieurs milieux d'entretien : milieu 199, Basal Eagle Medium, Minimum Essential Medium, milieu de SCHWÖBEL sans phos- phate (1), Hydrolysat de caséine en solution de EARLE; ou en varıant la quantité de sérum ( 5 p. 100, 2 p. 100, 0 p. 100) dans le milieu d'entretien; ou en augmentant la proportion de I'hydrolysat de lactalbumine dans le milieu jusqu'à 2 p. 100 (WEISS, 1959).

\section{$4^{0}$ Etude du pouvoir pathogène.}

Nous avons inoculé des veaux sensibles et des animaux de laboratoire avec les souches locales et NEETHLING. Nous avons choisi de jeunes veaux élevés à l'étable, dont nous étions sûrs qu'ils n'avaient pas contracté la maladie cuparavant. Les inoculations ont été faites par voie sous-cutanée à l'encolure, à raison de $3 \mathrm{ml}$ de culture cellulaire virulente pure. Tous les veaux inoculés (sauf deux) étaient de race métis Friesland, et âgés d'environ deux mois. Ils ont reçu différents passages des virus sur cellules rénales.

Les animaux de laboratoire ont été ınoculés par diverses voies : les cobayes, par voie intrapéritonéale $(1 \mathrm{ml})$, sous-cutanée $(1 \mathrm{ml})$, intramusculaıre $(1 \mathrm{ml})$, intracérébrale $(0,05 \mathrm{ml})$; les lapins par voie sous-cutanée $(1 \mathrm{ml})$, intraveineuse $(0,5 \mathrm{ml})$, intracérébrale $(0,05 \mathrm{ml})$, intrapéritonéale $(1 \mathrm{ml})$, intradermique $(0,1 \mathrm{ml})$; les souris, par voie sous-cutanée $(0,5 \mathrm{ml})$, intrapéritonéale $(0,5 \mathrm{ml})$, intraveineuse $(0,5 \mathrm{ml})$, intra-cérébrale $(0,02 \mathrm{ml})$; les souriceaux par voie sous-cutanée $(0,2 \mathrm{ml})$.

\section{Nature de l'acide nucléique des souches locales et Neethling.}

A l'aide d'un inhıbıteur de synthèse (5-Bromo désoxyuridine, ou 5 rodo-désoxyuridine), nous avons essayé d'inhiber la multiplication virale dans les cellules. Le virus vacanal qui se multiplie parfaitement sur cellules rénales de lapin nous a servi de virus à $A D N$ témoin. Chaque virus à caractériser (local ou NEETHLING) a

(1) Composition du milieu de SCHWOBEL :

$\mathrm{NaCl} . . . . . .8 \mathrm{~g}$ Hydrolysat de lactalbumine 1 $\mathrm{KCl} \ldots \ldots \ldots .0,3$ Sérum (facultatif) $\ldots \ldots \ldots 50 \mathrm{mb}$

$\mathrm{CaCl}_{2} \ldots \ldots .0,24$ Eau distıllée q. s. p...... 11

$\mathrm{MgSO}_{4} \ldots \ldots, 0,2$

$\mathrm{CO}_{3} \mathrm{HNa} \ldots 2$

Glucose..... 2 
été dilué à $10^{-1}$ solt dans le mılieu d'entretien ordinaire, soit dans ce même milieu contenant $20 \mathrm{mg} /$ litre de 5-Bromo désoxyuridine. Pour le virus vaccinal, nous avons falt 2 gammes de dilutions de $10^{-2}$ à $10^{-8}$, l'une dans le mılieu d'entretien normal, l'autre dans le mılıeu inhıbiteur. Toutes les dilutions ont été inoculées aux cellules rénales de lapin. Puis, après l'adsorption, les tubes inoculés avec les dilutions en milieu normal ont reçu le milieu d'entretıen normal ; les autres tubes ont reçu le milieu inhıbıteur. Durant l'incubation qui a duré 4 jours nous avons noté les résultats : lyse cellulaire ou inhibition de la replication virale.

\section{Hémagglutination.}

Nous avons falt réagir les souches locales et NEETHLING sur les hématies de veau, de mouton, de souris, de lapin, de poulet, solt à $25^{\circ} \mathrm{C}$, soit une nuit à $4^{\circ} \mathrm{C}$. Comme virus réactifs nous avions pris les surnageants de cultures cellulaires infectées, dilués du 1/4 au 1/512 dans un tampon physiologique.

\section{Séro-neutralisation.}

Deux souches 11 locale ef la souche NEETHLiNG), non diluées, ont été mélangées à un égal volume de chaque sérum à tester dilué au $1 / 10^{\mathrm{e}}$ et à du sérum normal témaın également dilué au $1 / 10^{\mathrm{e}}$. Les sérums à tester provenaient de veaux inoculés depuis 3 mois avec des broyats de nodules lyophilisés, chez lesquels Il s'était formé une intense réaction locale (œdème et adénite), suivie d'une ascension thermıque de quelques jours. Après une heure de neutralisatıon, les mélanges sérums-virus ont été inoculés aux cellules. L'observation des tubes a duré 5 jours pendant lesquels nous avons noté l'effet cytopathogène comparatıf des deux virus.

\section{Essai d'interférence avec le virus vaccinal.}

L'immunisation contre la dermatose se fassant au Kenya grâce au virus de la clavelée (WEISS, 1964), nous nous sommes demandés si une primoinfection avec le virus vaccinal ne protégerait pas les veaux contre la dermatose nodulare. Nous avons donc inoculé deux veaux avec du virus vaccinal lyophılısé, par voie intradermique. Puis 10 jours plus tard, ces veaux ont été éprou- vés avec les virus de la dermatose, par injection sous-cutanée.

\section{Remarques sur la conservation de ces souches.}

Nous avons cherché à conserver les propriétés de ces souches (pouvoir pathogène, effet cytopathogène) en les lyophılisanti en les congelant, ou en les plaçant à $4{ }^{\circ} \mathrm{C}$. Nous les avons lyophilisées et congelées, sous forme de nodules broyés, et de cultures cellulaires infectées. A $4^{\circ} \mathrm{C}$ nous avons stocké les virus sous forme de cultures cellulaires infectées en tubes hermétiquement bouchés, et à l'abri de la lumrère. Le contrôle de la vitalıté a été fait sur culture cellularre, et celur du pouvoir pathogène, par inoculation aux animaux.

\section{RÉSULTATS}

\section{Comportement des souches sur cellules} rénales de lapin.

a) Souches Sud-Africaines.

Le virus NEETHLING s'est multıplıé avec effet cytopathogène sur cellules rénales de lapin. Les virus ALLERTON et BZD n'ont provoqué aucun effet cytopathogène sur ces mêmes cellules et it ne semble pas qu'ils s'y soient développés. L'effet cytopathogène du virus NEETHLING a été beaucoup plus rapide ef plus complet que sur cellules rénales de veau, tout au moins sur la souche cellularre de rein de veau que nous possédons. Au 1er passage sur cellules rénales de lapin, l'effet cytopathogène a débuté aux $3 \mathrm{e}_{-} 4 \mathrm{e}$ jours. Il s'est formé des amas denses de cellules grisâtres, peu réfrıngentes, plus ou moins arrondies ou en fuseau. Ces amas étaient dispersés dans toute la nappe, et non plus seulement en bordure comme sur les cellules rénales de veau. Entre ces amas, la nappe se rétractait, s'effilochait ; les trous s'agrandissaient. Les cellules arrondies se détachaient du verre. En 2 ou 3 jours, la nappe a été complètement détruite. II ne restait que quelques îlots de cellules pycnotiques et granuleuses encore fixées au verre. Cet effet cytopathogène à son début est représenté sur la photo no 1, par comparaison avec la photo $n^{0} 2$ (cellules non inoculées). 


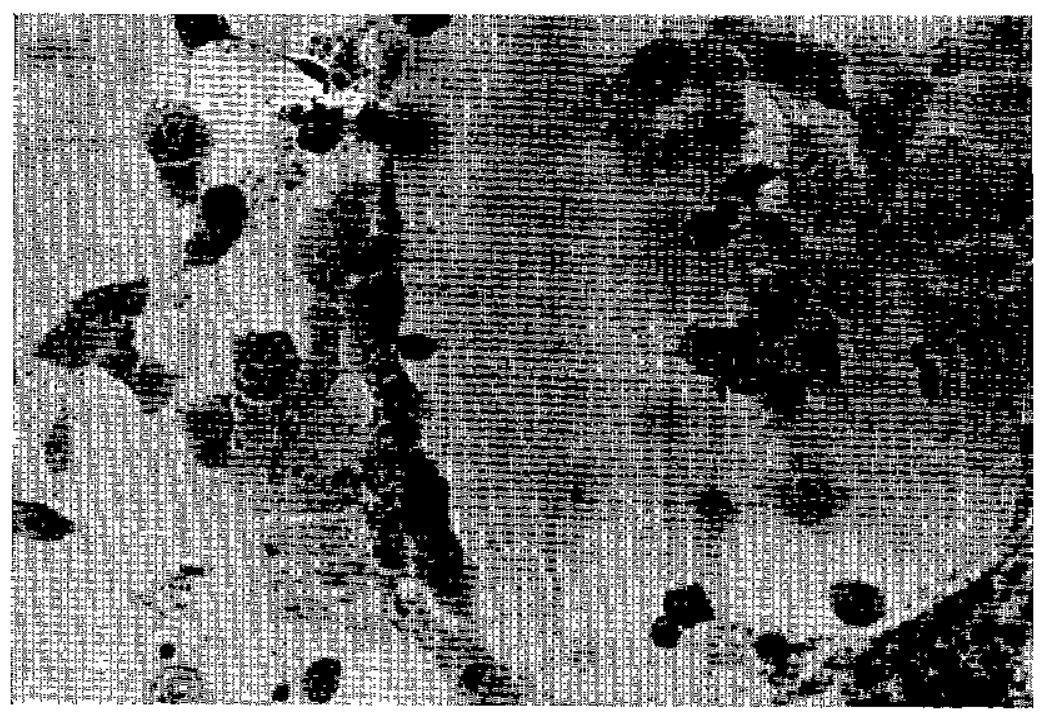

Photo 1. - Effet cylopathogène du virus NEETHLING sur les cellules rénales de lapin. Hématéine-éosine.

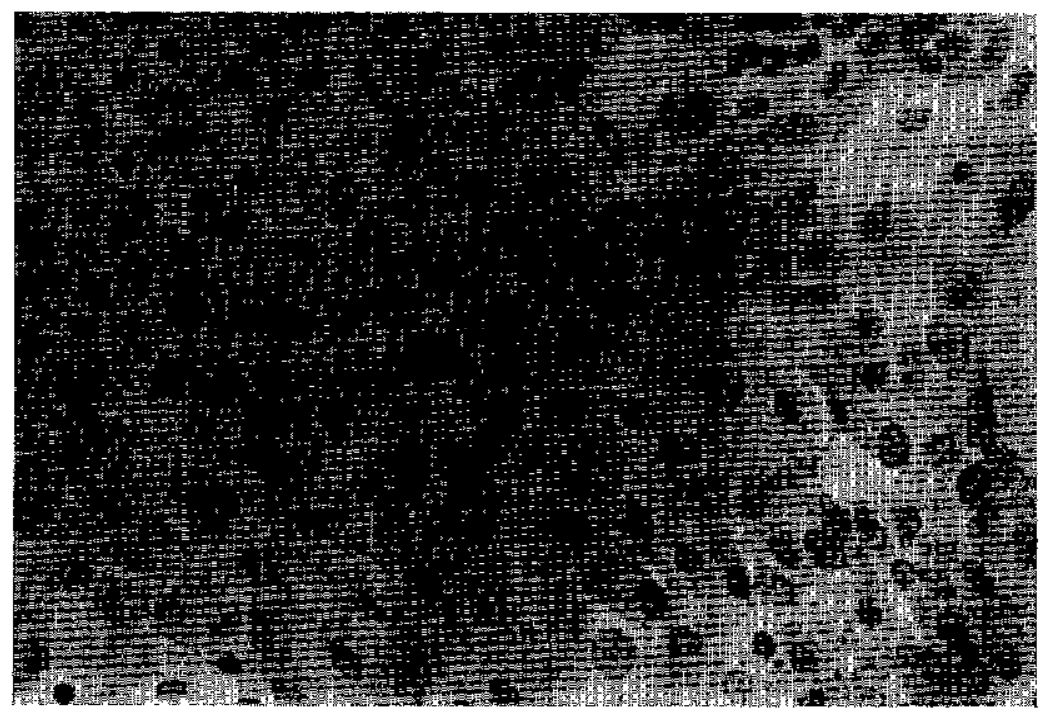

Photo 2. - Cellules rénales de lapin non inoculées. Hématéine-éosine.

Le virus NEETHLING a provoqué la formation dans les cellules rénales de lapin d'inclusions cytoplasmıques acidophiles analogues à celles induites dans les cellules rénales de veau. Ces inclusions étalent entourées d'un halo chromophobe clair ainsi que le montre la photo no 3.

Il est à remarquer que, seul parmı les 3 types, Sud-Africains, le virus NEETHLING provoque un effet cytopathogène sur cellules rénales de lapin. Ce caractère pourrait, s'il en était besonn, servir de diagnostic différentiel entre les 3 types.

b) Souches locales.

Isolées sur cellules rénales de veau, elles ont pu être passées avec succès sur cellules rénales de lapin. L'effet cytopathogène a été aussi rapide à partir du 10e passage, qu'avec le virus NEETHLING. Il était identıque et aussi complet (Photo 


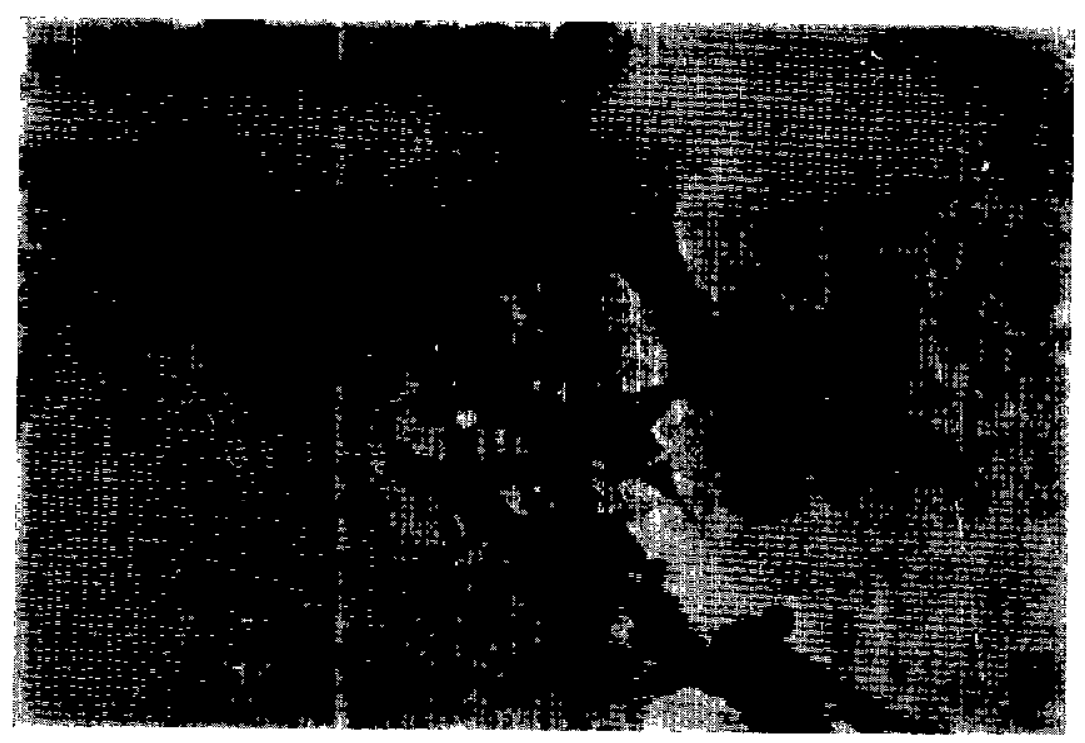

Photo 3. - Inclusions cyłoplasmıques éosinophıles induites par le virus NEETHLING dans les cellules rénales de lapin.

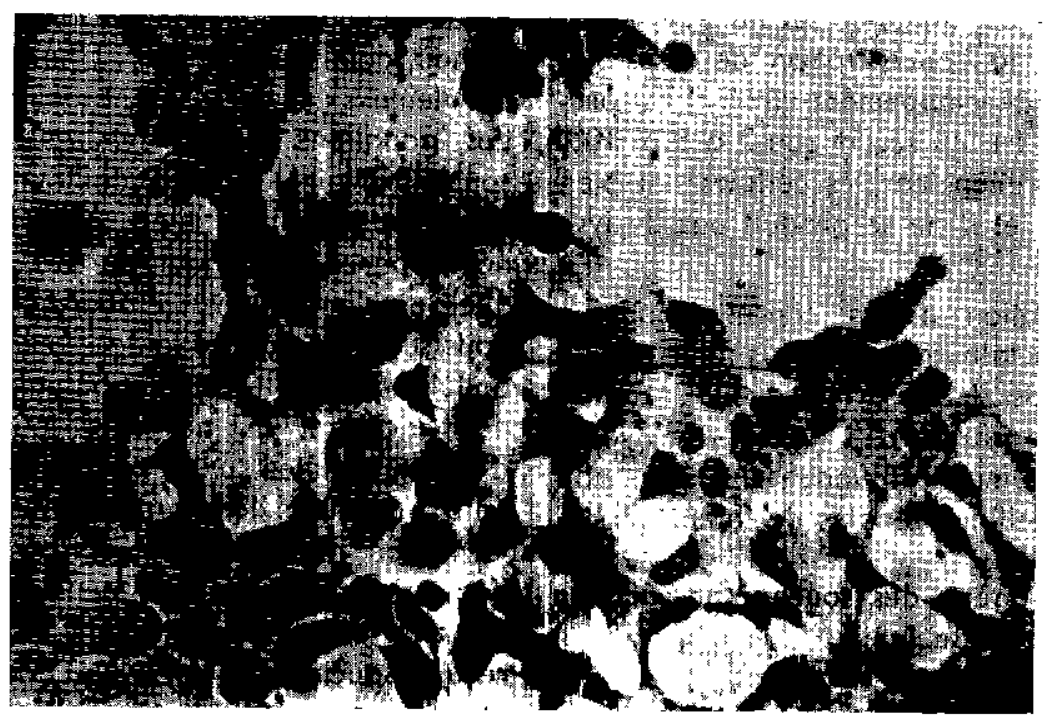

Photo 4. - Effet cytopathogène de la souche locale 507.

$\left.n^{\circ} 4\right)$. La coloration des cellules à l'hématéineéosine montrait les mêmes inclusıons cytoplasmiques éosinophiles (Photo $n^{0} 5$ ).

\section{$2^{\circ}$ Influence de divers facteurs sur le titre du virus.}

- La température d'ıncubation : A 35 oC le résultat n'a pas été meılleur qu'à $37^{\circ} \mathrm{C}$, et l'effet cytopathogène serait plutôt retardé.
- La composition du milieu de base : II n'y a pas eu de grandes variations dans le titre selon que l'on utilisalt le BEM (Basal Eagle Medium), le MEM (Mınımum Essential Medium), le milieu 199, le milıeu à l'hydrolysat de caséine, le milieu de SCHWOBEL. C'est encore avec le milieu $B E M$ que nous avons eu les résultats les plus constants.

Les titres habituels étaient de l'ordre de $10^{3,5}$ à $10^{4,5}$ DICT50 par $\mathrm{ml}$. 


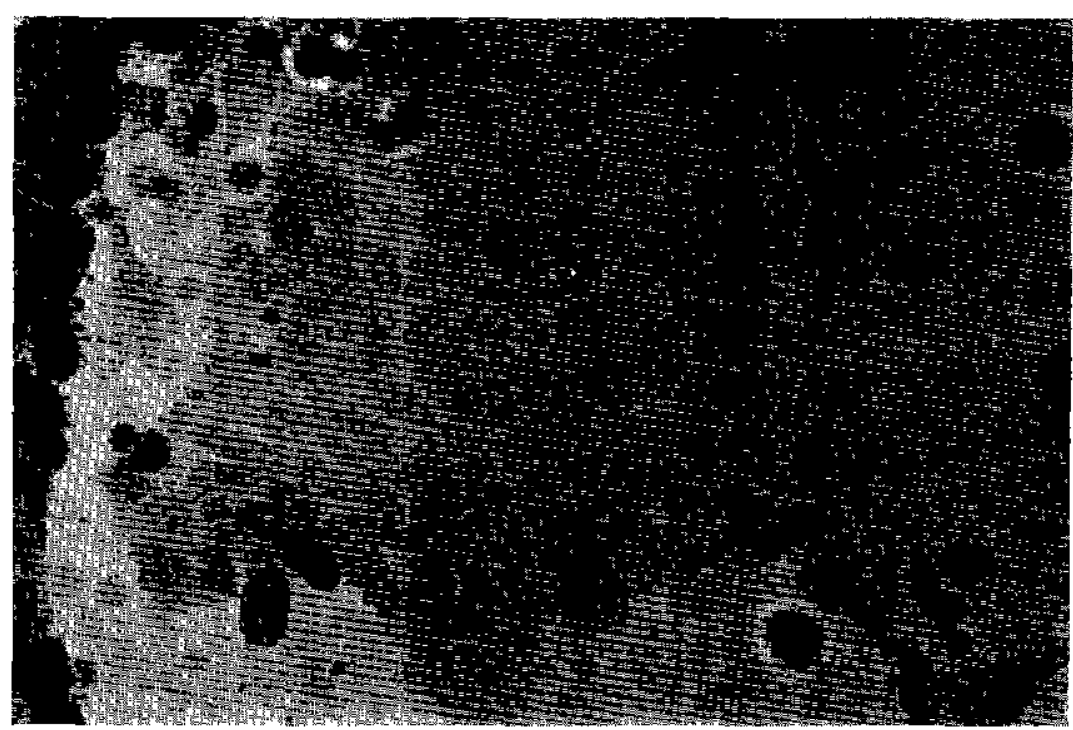

Photo 5. - Inclusions cytoplasmiques.

- La richesse du milieu en sérum : Le sérum normal jusqu'à la concentration de 5 p. 100 n'inhibe pas le développement viral. II est préférable d'adjoındre du sérum (de 2 à 5 p. 100) au milieu d'entretien, car les cellules ont bien meilleur aspect, ef Il ne se produit pas de lyse non spécifique.

- L'augmentation de la concentration en hydrolysat de lactalbumıne ne nous a pas donné de bons résultats. A 2 p. 1000 - concentration optima indiquée par WEISS (1959) - I'hydrolysat de lactalbumıne provoque une lyse non spécifique des cellules rénales de lapin.

\section{$3^{0}$ Pouvoir pathogène des souches passées sur cellules rénales de lapin.}

a) Description clinique de la malade expérimentale.

Les veaux inoculés avec les virus NEETHLING et locaux ont présenté des symptômes plus ou moins graves rappelant la maladie naturelle. Deux, en particulier, se sont remis difficlement après une évolution clinique caractéristique. L'un avait, reçu la souche NEETHLING au $12^{\mathrm{e}}$ passage sur cellules rénales de lapin ; l'autre, la souche locale 507 au 9 e passage. Au 6e jour après l'inoculation, leur température est montée à $40^{\circ} \mathrm{C}$ et. $40,5^{\circ} \mathrm{C}$. Ces veaux étaient prostrés, dyspnéiques et anorexiques. Au point d'inocu-
Iation s'est formé un œdème inflammatoire assez étendu, douloureux et dur. Une sécrétion mucopurulente s'écoulait des naseaux et des yeux. Les ganglions précruraux, préscopulaires ef sous-maxiliaires étaient douloureux et fortement hypertrophiés. L'éruption nodulaire cutanée apparve au $7 \mathrm{e}$ jour après l'inoculation, est allée en s'amplifiant : d'abord hérissement des poils sur l'encolure et le dos, formation de petits nodules perceptibles à la palpation au niveau de l'encolure, du dos, des joues, apparition d'autres nodules sur le périnée, les cuisses, les pattes, le flanc, le thorax; en fin d'évolution, formation d'ulcères purulents sur le mufle et dans les naseaux. L'état général des veaux a été très affecté, notamment pour celui ayant reçu la souche NEETHLING. La maladie a duré une quinzaine de jours; les veaux ont cependant guérı sans aucun traitement. La symptomatologie observée sur ces deux veaux a été identique à celle classiquement décrite pour la dermatose nodulaıre. La maladie a donc été reproduite sur des anımaux réceptifs, avec des souches virales ayant subi un certain nombre de passages sur cellules hétérologues. II est à remarquer que le virus 507 isolé d'une éruption bénigne sur zébus a pourtant causé une infection généralisée assez grave sur un jeune bovin sensible. Ce qu! montre la particulıère réceptivité du jeune animal, surtout s'il est de race sélectionnée. 
Les virus responsables ont été isolés sur les veaux inoculés expérımentalement, mais seulement à partır de nodules cutanés. Nous n'avons pas pu les retrouver dans le sang, bien que nous ayions prélevé du sang au début de la période d'hyperthermie. Les virus extraits des nodules se sont montrés cytopathogènes au premier passage sur cellules rénales de lapin. Ces résultats démontrent donc que les virus isolés sur cellules rénales de veau, et passés sur cellules rénales de lapin sont bien agents de la dermatose nodulaire et qu'ils se comportent comme la souche NEETHLING.

b) Pouvoir pathogène en fonction du nombre de passages sur cellules rénoles de lapin.

Jusqu'à maintenant, nous n'avons pas pu obtenir d'atténuation complète de ces souches après passages sur cellules rénales de lapin. ainsi que le montre le tableau 1.

TABLEAU I

Pouvoir pathogène des souches passêes sur cellules rénales de lapin

\begin{tabular}{|c|c|c|c|c|c|c|c|}
\hline Race & Age & Nombre & Souche & $\begin{array}{c}\text { Voie } \\
\text { d'inoculation }\end{array}$ & Inoculum & Volume & Réaction \\
\hline Friesland & 2 mois & ] & $\begin{array}{l}\text { Neethling } \\
\text { 12ème passage sur } \\
\text { cellules rênales de } \\
\text { lapin }\end{array}$ & sous-cutanée & $\begin{array}{l}\text { Culture cellulajire } \\
\text { conservée } 24 \text { h à }+4^{\circ}\end{array}$ & $3 \mathrm{ml}$ & $11+$ \\
\hline Friesiand & 2 mois & j & $\begin{array}{l}\text { Souche locale } 507 \\
\text { 9ême passage sur } \\
\text { cellules rếnales de } \\
\text { lapin }\end{array}$ & sous-cutanée & $\begin{array}{l}\text { Culture cellulaire } \\
\text { conservê } 24 \text { h à }+4^{\circ}\end{array}$ & $3 \mathrm{ml}$ & $H+$ \\
\hline Friesland & 2 mois & 1 & $\begin{array}{l}\text { Neethling } \\
\text { l2ème passage sur } \\
\text { cellules rénales de } \\
\text { lapin }\end{array}$ & sous-cutanée & $\begin{array}{l}\text { Culture cellulaire } \\
\text { canservé } 2 \text { mois à } \\
+4^{\circ}\end{array}$ & $3 \mathrm{~m} 1$ & 1 \\
\hline Friesland & 2 mois & 1 & $\begin{array}{l}\text { Neethling } \\
\text { l fème passage sur } \\
\text { cellules rênales de } \\
\text { lapin }\end{array}$ & sous-cutanée & $\begin{array}{l}\text { Culture cellulaire } \\
\text { conservée } 2 \text { mois à } \\
+4^{\circ}\end{array}$ & $3 \mathrm{ml}$ & + \\
\hline Friesland & 2 mois & 1 & $\begin{array}{l}\text { Souche locale } 507 \\
\text { 3ème passage sur } \\
\text { cellules rénales de } \\
\text { lapin }\end{array}$ & sous-cutanée & $\begin{array}{l}\text { Culture cellulaire } \\
\text { conservée } 2 \text { mois à } \\
+4^{\circ}\end{array}$ & $1,5 \mathrm{ml}$ & + \\
\hline Friesland & 2 mois & 4 & $\begin{array}{l}\text { Mélange de souches } \\
\text { 1yophili sées }\end{array}$ & sous-cutanëe & $\begin{array}{l}\text { Culture cellulaire } \\
\text { lyophilisée depuis } \\
4 \text { mois }\end{array}$ & $3 \mathrm{ml}$ & $H$ \\
\hline Friesland & 2 mois & 1 & $\begin{array}{l}\text { Neethling } \\
27 \text { ème passage sur } \\
\text { cellules rênales de } \\
\text { lapin }\end{array}$ & sous-cutanée & $\begin{array}{l}\text { Culture cellulaire } \\
\text { en find observation } \\
\text { (ECP maximum) }\end{array}$ & $3 \mathrm{ml}$ & +1 \\
\hline Métis & 2 mois & 1 & $\begin{array}{l}\text { Souche locale } 507 \\
21 \text { ème passage sur } \\
\text { cellules renales de } \\
\text { lapin }\end{array}$ & souş-cutanēe & $\begin{array}{l}\text { Culture cellulaire } \\
\text { en fin d'observation } \\
\text { (ECP maximum) }\end{array}$ & $3 \mathrm{ml}$ & 111 \\
\hline Metis & 2 mois & 1 & $\begin{array}{l}\text { Souche locale } 537 \\
2 \text { lème passage sur } \\
\text { cellules rénales de } \\
\text { lapin }\end{array}$ & sous-cutanée & $\begin{array}{l}\text { Culture cellulaire } \\
\text { en find observation } \\
\text { (ECP maximum) }\end{array}$ & $3 \mathrm{ml}$ & $H$ \\
\hline
\end{tabular}

Lëgende : $\rightarrow$

Oedème local au point d'injection, hyperthermie

H Oedème local, hyperthermie, réaction ganglionnaire, rares nodules.

H idem $H$, mais nodules nombreux

HH Dedème local, hyperthermie, réaction ganglionnaire, nombreux nodules, secrêtion oculo-tnasale muco-purulente, amaigrissement marquê, état gênêral affecté. 
Nous constatons d'après ce tableau que, même après 21 passages (souches locales) ou 27 passages (NEETHLING) sur cellules rénales de lapin, les souches demeurent encore relativement pathogènes pour les veaux. II est possible que le nombre de passages soit insuffisant pour une atténuation plus marquée, ou même que les passages sur cellules rénales de lapin n'entraînent aucune atténuation de ces souches. Nous continuons les passages pour nous en rendre compte.

c) Inoculation des animaux de laborotore.

Aucun des animaux de Iaboratoire inoculés avec les souches locales ou NEETHLING n'a présenté de symptôme particulier. II semble done que ces virus ne soient pas pathogènes pour les animaux de laboratoire.

\section{$4^{\circ}$ Nature de l'acide nucléique.}

Les souches locales et NEETHLING ne se sont pas multipliées sur cellules rénales de lapin, en présence de 5-Bromo désoxyuridine. De même, le virus vaccinal a été inhıbé complètement à partir de la dilution $10^{-3}$, comme inoculum. Nous en concluons que l'acide nucléique des souches locales et NEETHLING est de l'acide désoxyribonucléique.

\section{$5^{\circ}$ Hémagglutination.}

Aucune des souches examınées ne s'est montrée hémagglutinante pour les hématies de veau, mouton, lapin, poulet et souris.

\section{$6^{0}$ Séro-neutralisation.}

La teneur en antıcorps des sérums utilısés était faible. A la dilution au $1 / 10$ e, un sérum neutralisait complètement les 2 souches, 3 sérums neutralisalent presqu'entièrement, 2 sérums neutralisaient très peu. Les 2 souches étaient neutralisées d'une façon analogue, ce qui confirme leur parenté présumée d'après leur effet cytopathogène.

\section{7o Essai d'interférence avec le virus vaccinal.}

Les inoculations à des veaux ont montré que la prima-infection par le virus vaccinal ne protégeait pas ceux-cl contre une surinfection avec le virus de la dermatose nodulaire. Le résultat nous a un peu surpris, comple tenu du fait qu'au Kenya on vaccine contre la dermatose nodulaire grâce au virus claveleux (WEISS, 1964), et qu'il semblait donc y avolr une parenté assez proche entre le virus de la dermatose et ceux du groupe POX. Cependant une étude récente (LIEBERMAN, 1968) a montré qu'il n'y avait pas de parenté immunologique étroite entre le virus de la dermatose nodulaire ef certains virus du groupe POX, dont en part1culier le virus vaccinal. Ce qui est en accord avec nos propres résultats.

\section{8o Vitalité des souches après conservation}

Le contrôle de vitalité des souches conservées en culture cellulaire ou sous forme de nodules broyés nous a donné les résultats suivants : A 4 oC, à l'obscurité et en tubes bouchés hermétiquement, le virus de culture cellulaire se conserve au moins pendant 6 mois. Au congélateur $\left(-20^{\circ} \mathrm{C}\right)$, les cultures cellulares lyophilısées (sans excipient) gardent leur virulence au moins pendant 7 mois. Un échantillon a perdu son infectiosité après 10 mois. Les nodules lyophılisés peuvent conserver le virus pendant 9 mols. II semble, d'après plusieurs essais, que le virus se conserve très mal dans les cultures cellulaires congelées.

\section{CONCLUSION}

Les souches virales de dermatose nodulaire malgache présentent des caractères identiques à ceux de la souche NEETHLING Sud-Africaine: adaptabilité aux celluies rénales de lapin, formation d'inclusions dans ces cellules, séro-neutralısation comparable, pouvoir pathogène similaire, acide nucléıque identıque, absence de propriété hémagglutinante. Ces souches sont nettement distinctes des virus ALLERTON et $B Z D$, lesquels d'autre part ne s'adaptent pas aux cellules rénales de lapin. Elles n'ont pas de parenté immunologique proche avec le virus vaccinal, bien que celui-ci provoque sur cellules rénales de lapin un effet cytopathogène identique, et qu'il comporte également de l'ADN.

Institut d'Elevage et de Médecine vétérnnaire des Pays tropicaux, Laboratoire Central de l'Elevage, Tananarive. 


\section{SUMMARY}

Adaptation to the rabbif renal cells of viruses associated with the bovine lumpy skin disease

The local and NEETHLING strains, agenis of lumpy skin disease were adapied to the rabbit renal cells. They induce the cell destruction and the development of cytoplasmic inclusions. After a number of passages, the viral strains are still pathogenic for calf. The sero-neutralization shows the identify between the local and NEETHLING strains. They are not hemagglutinants; their nucleic acid is DNA.

\section{RESUMEN}

Adaptación a las células renales del conejo de virus asociados con la dermatosis nodular de los bovinos

Se adaptaron las cepas locales y NEETHLING, agenies de la dermatosis nodular, a las células renales del conejo. Provocan la destrucción de las células y la formación de inclusiones citoplasmicas. Después de un cierto número de pasajes, las cepas virales son todavía patógenas para el ternero. La sero-neutralización muestra la identidad enfre las cepas locales y NEETHLING. No son hemaglutinantes. Su ácido nucleico es el ADN.

\section{BIBLIOGRAPHIE}

ALEXANDER (R. A.), et HAIG (D. A.). - Travail non publié, 1956.

ALEXANDER (R. A.), PLOWRIGHT (W.) et HAIG (D. A.). - Cytopathogenic agents associated with lumpy skin disease. Bull. Epizoot. Dis. Africa, 1957, 5 (4), 489-492.

HAIG (D. A.). - Lumpy skin disease. Bull. Epizoot. Dis. Africa, 1949, 1957, 5 (4), 421-430.

LANGE ( $M$. de). -- The histology of the cytopathogenic changes produced in monolayers epithelial cultures by viruses associated with lumpy skin disease. Onderstepoort. J. Vet. Res., 1959, 28 (2), 245-255.

LIEBERMAN (H.). - Comparative immuno-histological studies on cell-cultures infected with para-vaccinia viruses. Vet. Bull, 1968, 38, p. 684.

PRYDIE (J.) et COACKLEY (W.). — Lumpy skin disease. Tissue cultures studies. Bull. Epizoot. Dis. Africa, 1959, 7 (1), 37-50.
VAN DEN ENDE (M.), ALEXANDER (R. A.), DON (P.) et KIPPS (A.). - Isolation in chicken embryon of a filterable agent possibly related efiologically to lumpy skin disease of cattle. Noture, 1948, 161, 4092, 526.

VAN ROOYEN (P. J.), KUMM (N. A. L.), WEISS (K. E.) et ALEXANDER (R. A.). A preliminary note on the adaptation of a strain of lumpy skin disease virus to propagation in embryonated eggs. Bull. Epizoot. Dis. Africo, 1959, 7 (1), 79-85.

WEISS (K. E.) et GEYER (S. M.). - The effect of lactalbumin hydrolysate on the cytopathogenesis of Jumpy skin disease virus in tissue culture. Bull. Epizoof. Dis. Africa, 1959, 7 (3), 243-254.

WEISS (K. E.). - La dermatose nodulaire in : Maladies nouvelles des animaux. Rome, FAO (Etude agricole, no 61), 1964, Pp. 189-216. 